\title{
Maternal Alcohol Consumption During Pregnancy and Physical Outcomes up to 5 Years of Age: A Longitudinal Study
}

\author{
Frances V. O'Callaghan ${ }^{\text {, }}$ Michael O'Callaghan ${ }^{\text {b, }}$, Jake M. \\ Najman ${ }^{\mathrm{c},}$ Gail M. Williams ${ }^{\mathrm{d}}$ and William Bor ${ }^{\mathrm{e}}$
}

\author{
${ }^{a}$ School of Applied Psychology, Griffith University, Gold Coast, Queensland, Australia \\ ${ }^{b}$ Mater Misericordiae Hospital, Raymond Terrace, South Brisbane, Queensland 4101, Australia \\ ${ }^{c}$ Department of Anthropology and Sociology, The University of Queensland, Brisbane, Queensland, Australia \\ ${ }^{d}$ Australian Centre for International and Tropical Health and Nutrition, \\ The University of Queensland, Brisbane, Queensland, Australia \\ ${ }^{e}$ Department of Obstetrics and Gynecology, The University of Queensland, Brisbane, Queensland, Australia
}

Abstract

Aim: To examine whether alcohol exposure in pregnancy affects weight and head circumference (HC) at birth and 5 years, and whether these effects are independent of cigarette exposure in pregnancy and social disadvantage.

Study design: The Mater-University Study of Pregnancy (MUSP) involves a prospective cohort of 8556 mothers who were enrolled at first antenatal visit. The quantity and frequency of alcohol consumption in early and late pregnancy and a measure of binge drinking in early pregnancy were recorded. Weight and HC were measured on children seen at birth and at 5 years. Level of cigarette use in early pregnancy and maternal age and level of education and family income were also measured.

Results: Light and moderate alcohol consumption in early or later pregnancy had no independent effects on weight or $\mathrm{HC}$ at birth or 5 years. Binge drinking in early pregnancy was not associated with restricted HC, and there was no effect modification by concurrent cigarette use in early pregnancy. An apparent effect of alcohol in late pregnancy on birth weight was due to confounding by cigarette use, with social risk being an independent predictor.

Conclusion: Alcohol ingestion up to moderate levels in pregnancy was not associated with deficits in either weight or $\mathrm{HC}$ at birth or at 5 years.

Keywords: maternal alcohol consumption; pregnancy; head circumference; birth weight; 5-year outcomes; social risk; maternal smoking

\section{Introduction}

Growth restriction is part of the pattern of abnormalities that occur in children with fetal alcohol syndrome (FAS) [1]. Because of variation in patterns of growth in different organs during fetal development, timing of alcohol exposure is thought to influence type of fetal growth restriction. In early pregnancy, when neuronal multiplication and organ formation are occurring, the effects of alcohol may result in craniofacial anomalies, organ malformations, microcephaly, or a normal-sized brain with decreased cells. Fetal damage occurs as a result of either decreased cellular proliferation or cell death [2]. Alcohol exposure later in pregnancy may affect pre- and post-natal growth [2-5], with the effect occurring principally by inhibiting the uptake of nutrients, thereby causing malnutrition [4-7]. Further, the effects of alcohol may be increased by social factors, as well as maternal smoking, where there is evidence that tobacco reduces fetal oxygenation as well as the levels of certain nutrients [8].

Most studies of the effects of maternal alcohol consumption on offspring growth have focused on effects at birth. These studies have reported deficits in weight [9-23], length [10-13,19,20,22], and head circumference (HC) [10,11,15,19,20,22-25]. Several others have measured children at later ages and also found effects on various growth parameters [26-30]. 
In contrast, a number of studies have found no deleterious effects on one or more of these growth parameters at birth [9,12,24,30-42], at 12 months [12,41], 24 months [12], and at 4, 7, and 14 years [42]. The different findings between studies reflect a number of factors such as the duration and amount of alcohol use among different samples with findings for moderate levels of alcohol exposure being more inconsistent. Definitions of moderate drinking vary, however, with most studies considering this to be in the range of less than one drink to less than two drinks per day. In the current research, half to less than one drink per day is considered to be moderate drinking, and less than half a drink per day is considered to be light drinking. Other factors include failure to control for variables that may potentially confound the association between alcohol use and pregnancy outcomes (e.g. cigarette smoking-a factor that may have a synergistic effect with alcohol) [43], and differences in the characteristics of the samples investigated (e.g. low versus high SES). Day [44] notes that studies that have found continued growth deficits in prenatally exposed children are of lower income cohorts, whereas those that have not had this result generally used samples of higher socioeconomic status.

The Mater-University Study of Pregnancy (MUSP) is a prospective longitudinal study of social, psychological, and obstetric factors in pregnancy. The current study investigates outcomes relating to weight and HC from this Australian cohort who have been assessed at birth and at 5 years. Maternal alcohol consumption measures included the quantity and frequency of consumption measured at various stages of pregnancy, as well as the pattern of consumption as reflected in a measure of binge drinking. The aims of this study were to examine whether alcohol exposure in pregnancy, including binge drinking in early pregnancy, affects growth in weight and $\mathrm{HC}$ at birth and 5 years, and whether these effects, if present, are independent of cigarette exposure in pregnancy and social disadvantage. Specific study hypotheses were that binge drinking in early pregnancy would lead to adverse and long-term effects on head growth, and that concomitant cigarette and alcohol exposure in early pregnancy would have a synergistic effect on restricted head growth.

\section{Methods}

The Mater-University Study of Pregnancy initially involved 8556 women enrolled between 1981 and 1984 at their first antenatal visit to the Mater Misericordiae Mothers' Hospital, Brisbane. Details of the cohort [45] and of those lost to follow-up [46,47] have been described previously. Mothers lost to followup were likely to be younger, single, less well educated, socially more disadvantaged, and their children more premature and of lower birth weight. A total of 7617 singleton infants were born at the hospital, and of these, 6320 also had HC measured at birth. Birth weight and head circumference were measured in the delivery suite or triage nursery following Caesarian section delivery. Head circumference was measured by a paper tape. When the measurement was recorded in the MUSP database, however, all values within each centimetre interval were recorded as the midpoint of that interval (e.g. values between 34.0 and $34.9 \mathrm{~cm}$ were recorded as $34.5 \mathrm{~cm}$ ). At 5 years, exact HC and weight measures were taken on 4076 children with 4038 of these children having complete information on maternal alcohol consumption. Length was not included as it was less consistently measured at birth. No other physical measures were taken at the 5-year assessment. The z scores adjusting for age and gender were calculated for weight and $\mathrm{HC}$ at birth and 5 years using the British Growth Data included in a detailed health and psychosocial questionnaire completed by mothers [48]. Based on these $\mathrm{z}$ scores, the children were classified into three groups ( $<$ 3rd, 3rd to $<10$ th, and $\geq 10$ th percentile within the study population) for each of these weight and HC measures.

The frequency of alcohol consumption in early pregnancy was measured at the first pregnancy visit (mean 19.8 F 6.0 weeks) with the following question: "How often do you drink alcohol since becoming pregnant?” Responses consisted of daily, a few times a week, a few times a month, a few times a year, rarely, and never. Consumption in late pregnancy was assessed using a similar questionnaire and asking mothers, shortly after delivery: "In the last three months of your pregnancy, how often did you drink alcohol?” Responses consisted of daily, a few times a week, a few times a month, and not at all. To assess the quantity of consumption, respondents were asked on both occasions, "How much alcohol do you usually drink at those times?” Responses consisted of seven or more glasses, five or six glasses, three or four glasses, one or two glasses, less than one glass, and never drink.

Each consumption frequency was given a loading: daily $=365$; a few times/week = 156; a few times $/$ month $=36$; a few times/year $=5$; rarely $=2$; and never $=0$. Loadings were then assigned to each quantity using a similar format to previous research [49]: seven or more glasses = 8; five or six glasses = 5.5 ; three or four glasses $=3.5$; one or two glasses $=1.5$; less than one glass $=0.5$; and never drank $=0$. To calculate the average number of glasses per day, the frequency was multiplied by the quantity and then divided by 365 . The average number of glasses per day was then multiplied by 0.5 to obtain the 
daily average ounces of absolute alcohol (AA; since $0.5 \mathrm{oz}$ AA $=1$ glass). The four final alcohol consumption categories used in further analyses were as follows (oz AA/day): 0; 0.01-0.249; 0.250.499 ; and 0.5 or more, being equivalent to nil, $<1 / 2$ glass, $1 / 2-<1$ glass, and $>1$ glass/day. Binge drinking was measured only at the first pregnancy visit by the question, "When you drink alcohol what part of the time do you have at least 5 glasses?” Responses were coded as nearly half the time or more, less than half the time, and never.

Cigarette use was measured as the number and frequency recorded at the first hospital visit and coded as nil, 1-10/day, 11-20/day, and >20/day. A social risk score was computed from the following information which was provided at the first visit: maternal age $(<20$ years $=1)$; maternal education (incomplete high school =1); and family income $(<\$ 10399 /$ year $=1)$. Family income at this level included the lower third of the cohort. The total social risk score consisted of the sum of the three measures and ranged from 0 to 3 . Scores of 2 or 3 were combined into one high-risk category due to smaller numbers in these groups.

\section{Statistical analysis}

The relationship between maternal drinking during early and late pregnancy and HC and weight at birth and at 5 years of age was examined. Statistical significance was assessed by the chi-squared test, as well as several one-way between-groups analyses of variance. Analyses were performed using SPSS v. 10. Potential confounding factors were examined using multiple linear and logistic regression. Possible effect modification of cigarette exposure on alcohol-mediated effects was examined using the approach of Kahn and Sempos [50]. A two-tailed p value of $<0.05$ was taken to indicate statistical significance.

\section{Results}

About 50\% (early pregnancy) and 36\% (late pregnancy) of the women in the current study reported that they drank alcohol during their pregnancy. The average consumption of drinkers was $0.146 \mathrm{oz}$ AA/day (between 1/3 and 1/4 glass/day or 2 glasses/week) in early pregnancy and $0.074 \mathrm{oz}$ AA/day (about 1/7 glass/day or 1 glass/week) in late pregnancy. Binge drinking in early pregnancy was reported by $20 \%$ of the women on at least one occasion.

Examination of loss to follow-up from first pregnancy visit $(n=8556)$ to those with a HC measurement at birth $(n=6320)$ showed that groups were similar in patterns of alcohol consumption, maternal age, and maternal education. There was, however, a differential loss to follow-up of those with lower income $(p=0.01)$. At birth, those with a HC measure were generally similar to babies without a HC measure (apart from alcohol in late pregnancy), while at 5 years, mothers lost to follow-up were younger, less well educated, poorer, and consumed more alcohol (Table 1). The magnitude of these differences, however, was generally small.

The relationship between level of alcohol exposure in pregnancy and $\mathrm{HC}$ and weight at birth and at 5 years is shown in Table 2. Both measures of alcohol exposure in early pregnancy were unrelated to HC at birth or 5 years. Similar nonsignificant differences were also found when mean z HC scores were compared for different levels of alcohol exposure. For alcohol in late pregnancy, those consuming more than 1 glass/day had a higher prevalence of $\mathrm{HC}<$ 3rd percentile $(\mathrm{p}=0.03)$, though numbers were small and no differences were evident when comparing mean z HC scores across these levels of alcohol consumption. Although statistically significant results were also found for alcohol in late pregnancy and $\mathrm{HC}$ at 5 years, those in the highest drinker category were similar to nondrinkers and there was no consistent trend evident in the results across levels of alcohol exposure and no differences evident when mean $z$ HC scores were compared. 
Table 1

Comparison of those with or without HC measurements at birth, and at 5 years within birth cohort

\begin{tabular}{|c|c|c|c|c|}
\hline \multirow[t]{3}{*}{ Measure } & \multicolumn{2}{|l|}{ Birth (HC) } & \multicolumn{2}{|l|}{5 Years $(\mathrm{HC})$} \\
\hline & Yes $(n=6433)$ & No $(n=1331)$ & Yes $(n=4076)$ & No $(n=3688)$ \\
\hline & $\%$ & $\%$ & $\%$ & $\%$ \\
\hline \multicolumn{5}{|l|}{ Maternal age } \\
\hline $13-19$ & 16.8 & 15.6 & 13.3 & 20.2 \\
\hline $20-34$ & 78.7 & 79.4 & 81.7 & 75.6 \\
\hline \multirow[t]{2}{*}{$\geq 35$} & 4.5 & 5.0 & 5.0 & 4.2 \\
\hline & $p=0.4$ & & $p<0.001$ & \\
\hline \multicolumn{5}{|l|}{ Maternal education } \\
\hline Incomplete high school & 18.9 & 18.2 & 17.4 & 20.3 \\
\hline Complete high school & 63.8 & 63.6 & 64.2 & 63.4 \\
\hline \multirow[t]{2}{*}{ Post high school } & 17.2 & 18.2 & 18.4 & 16.3 \\
\hline & $p=0.7$ & & $p<0.001$ & \\
\hline \multicolumn{5}{|l|}{ Family income } \\
\hline$<\$ 10,399$ & 34.9 & 36.1 & 30.9 & 40.1 \\
\hline \multirow[t]{2}{*}{$\geq \$ 10,399$} & 65.1 & 63.9 & 69.1 & 59.9 \\
\hline & $p=0.4$ & & $p<0.001$ & \\
\hline \multicolumn{5}{|c|}{ Alcohol-early pregnancy (glasses/day) } \\
\hline Nil & 50.1 & 53.0 & 49.4 & 51.8 \\
\hline$>0$ to $<1 / 2$ & 45.5 & 43.4 & 46.8 & 43.2 \\
\hline $1 / 2$ to $<1$ & 2.7 & 2.8 & 2.3 & 3.2 \\
\hline \multirow[t]{2}{*}{$\geq 1$} & 1.7 & 0.8 & 1.5 & 1.7 \\
\hline & $p=0.045$ & & $p<0.002$ & \\
\hline \multicolumn{5}{|l|}{ Binge drinking } \\
\hline Nil & 78.4 & 79.2 & 79.8 & 77.0 \\
\hline$<$ half time & 78.1 & 17.9 & 17.2 & 19.1 \\
\hline \multirow[t]{2}{*}{$\geq$ half time } & 3.5 & 2.9 & 3.0 & 3.9 \\
\hline & $p=0.5$ & & $p<0.006$ & \\
\hline \multicolumn{5}{|c|}{ Alcohol-late pregnancy (glasses/day) } \\
\hline Nil & 64.3 & 66.7 & 63.7 & 65.8 \\
\hline$>0$ to $<1 / 2$ & 30.2 & 29.9 & 31.4 & 28.7 \\
\hline $1 / 2$ to $<1$ & 3.6 & 2.7 & 3.3 & 3.6 \\
\hline \multirow[t]{2}{*}{$\geq 1$} & 2.0 & 0.6 & 1.6 & 1.9 \\
\hline & $p=0.004$ & & $p<0.06$ & \\
\hline
\end{tabular}


Table 2

Relationship between level of alcohol exposure in pregnancy and percentage of children with restricted growth in $\mathrm{HC}$ and weight at birth and 5 years

\begin{tabular}{|c|c|c|c|c|c|c|c|c|c|c|c|c|}
\hline \multirow[t]{3}{*}{ Measure } & \multicolumn{6}{|c|}{ Head circumference } & \multicolumn{6}{|c|}{ Weight } \\
\hline & \multicolumn{3}{|l|}{ Birth } & \multicolumn{3}{|c|}{5 Years } & \multicolumn{3}{|l|}{ Birth } & \multicolumn{3}{|c|}{5 Years } \\
\hline & $N$ & $<3$ & $3-10$ & $N$ & $<3$ & $3-10$ & $N$ & $<3$ & $3-10$ & $N$ & $<3$ & $3-10$ \\
\hline \multicolumn{13}{|c|}{ Alcohol-early pregnancy (glasses/day) } \\
\hline Nil & 3164 & 3.6 & 5.7 & 2002 & 3.2 & 7.4 & 3852 & 2.9 & 6.9 & 1995 & 3.4 & 7.5 \\
\hline$>0$ to $<1 / 2$ & 2876 & 3.1 & 5.8 & 1896 & 2.7 & 6.6 & 3438 & 2.9 & 7.1 & 1892 & 2.6 & 6.3 \\
\hline $1 / 2$ to $<1$ & 172 & 2.9 & 7.0 & 92 & - & 5.4 & 208 & 4.3 & 5.3 & 92 & 2.2 & 6.5 \\
\hline \multirow[t]{3}{*}{$\geq 1$} & 108 & 3.7 & 3.7 & 59 & 3.4 & 8.5 & 119 & 4.2 & 11.8 & 59 & - & 13.6 \\
\hline & $\chi^{2}(d f)$ & \multicolumn{2}{|c|}{$2.99(6)$} & & \multicolumn{2}{|c|}{$5.31(6)$} & \multicolumn{3}{|c|}{$7.4(6)$} & \multicolumn{3}{|c|}{$10.4(6)$} \\
\hline & $p$ & \multicolumn{2}{|l|}{0.8} & & \multicolumn{2}{|c|}{0.05} & \multicolumn{3}{|c|}{0.3} & \multicolumn{3}{|c|}{0.11} \\
\hline \multicolumn{13}{|c|}{ Binge drinking } \\
\hline Nil & 4932 & 3.3 & 5.4 & 3220 & 2.9 & 6.9 & 5952 & 2.8 & 6.6 & 3208 & 2.8 & 7.1 \\
\hline$<$ Half time & 1141 & 3.9 & 7.2 & 694 & 2.9 & 7.8 & 1372 & 3.6 & 8.8 & 695 & 3.5 & 5.8 \\
\hline \multirow[t]{3}{*}{$\geq$ Half time } & 219 & 2.3 & 6.4 & 119 & 3.4 & 5.9 & 256 & 3.1 & 7.8 & 119 & 1.7 & 10.1 \\
\hline & $\chi^{2}(d f)$ & \multicolumn{2}{|c|}{$7.45(4)$} & & \multicolumn{2}{|c|}{$1.0(4)$} & \multicolumn{3}{|c|}{$11.8(4)$} & \multicolumn{3}{|c|}{$4.7(4)$} \\
\hline & $p$ & \multicolumn{2}{|c|}{0.11} & & \multicolumn{2}{|c|}{0.9} & \multicolumn{3}{|c|}{0.02} & \multicolumn{3}{|c|}{0.3} \\
\hline \multicolumn{13}{|c|}{ Alcohol-late pregnancy (glasses/day) } \\
\hline Nil & 3913 & 3.5 & 5.7 & 2544 & 3.5 & 7.7 & 4378 & 2.8 & 7.2 & 2537 & 3.2 & 6.9 \\
\hline$>0$ to $<1 / 2$ & 1839 & 2.7 & 5.5 & 1252 & 2.1 & 5.7 & 2209 & 2.5 & 6.7 & 1248 & 2.7 & 7.1 \\
\hline $1 / 2$ to $<1$ & 217 & 2.3 & 6.9 & 132 & 1.5 & 5.3 & 251 & 2.8 & 7.6 & 132 & 0.8 & 9.1 \\
\hline \multirow[t]{3}{*}{$\geq 1$} & 120 & 8.3 & 5.8 & 63 & 3.2 & 9.5 & 128 & 3.1 & 7.8 & 63 & 4.8 & 11.1 \\
\hline & $\chi^{2}(d f)$ & \multicolumn{2}{|c|}{$13.9(6)$} & \multicolumn{3}{|c|}{$14.1(6)$} & & 1.8 & & & 5.97 & (6) \\
\hline & $p$ & 0.03 & & & 0.03 & & & 0.94 & & & 0.4 & \\
\hline
\end{tabular}

Binge drinking in early pregnancy was associated with restricted birth weight for both categories of binge drinking, and this effect was also evident in the differences in mean $z$ scores for birth weight: no binge-mean $z$ score $=0.21(0.98)$, binge occasionally-mean $z$ score $=0.08(1.0)$, and binge more than half the time-mean $z$ score $=0.002(0.9), d f=(2,7577), F=14.0, \mathrm{p}<0.001$. No effect was evident at 5 years on this or other measures of alcohol exposure.

The relationship between binge drinking and cigarette use in early pregnancy and HC and birth weight is shown in Table 3. There was no evidence of effect measure modification, with cigarette exposure and not binge drinking adversely affecting HC and birth weight. This supports the findings in the univariate analyses.

To further explore the relationship of binge drinking to birth weight present in the univariate analysis, and its independence from level of cigarette exposure in early pregnancy and level of social risk, a multiple linear regression was performed. Social risk was related to birth HC and birth weight, and to $\mathrm{HC}$ at 5 years but not to weight at 5 years. The regression was performed with $z$ score for birth weight as the dependent variable and binge drinking (nil versus any binge drinking) included as a predictor variable. The addition of cigarette smoking (included as three dummy variables for levels of smoking compared to not smoking) but not social risk (included as two dummy variables with low risk as the reference category) leads to the relationship between binge drinking and birth weight becoming of small magnitude and no longer being statistically significant $(B=-0.142, p<0.001$ to $B=-0.02, p=0.4)$. Similar conclusions resulted from a logistic model with birth weight $<10$ th percentile as the dependent variable (odds ratio $1.34,95 \%$ CI: $(1.28,1.6)$ to odds ratio of 1.0 with inclusion of cigarette smoking). The apparent relationship between binge drinking and birth weight was due to confounding by level of cigarette smoking. Both level of smoking and social risk were, however, independent predictors of birth weight. Though the relationship between level of drinking in late pregnancy and HC at birth and 5 years was statistically significant, the inconsistency of the effect and its restriction to a small number of individuals in the highest exposure category limited further analysis. 
Table 3

Relationship between binge drinking and cigarette categories in early pregnancy and percentage of children with restricted growth in $\mathrm{HC}$ and birth weight

\begin{tabular}{|c|c|c|c|c|c|c|}
\hline & \multicolumn{3}{|c|}{ Head circumference } & \multicolumn{3}{|c|}{ Birth weight } \\
\hline & $N$ & $<3$ & $3-10$ & $N$ & $<3$ & $3-10$ \\
\hline No binge/no cigarettes & 3316 & 2.5 & 4.4 & 4008 & 1.8 & 4.9 \\
\hline Binge/no cigarettes & 500 & 2.4 & 7.0 & 616 & 1.8 & 4.4 \\
\hline No binge/cigarettes & 1598 & 4.9 & 7.5 & 1922 & 4.8 & 10.1 \\
\hline \multirow[t]{3}{*}{ Binge/cigarettes } & 854 & 4.2 & 7.1 & 1006 & 4.6 & 11.1 \\
\hline & $\chi^{2}(d f)$ & \multicolumn{2}{|l|}{$48.3(6)$} & & \multicolumn{2}{|l|}{$149.5(6)$} \\
\hline & $p$ & \multicolumn{2}{|l|}{$<0.001$} & & \multicolumn{2}{|l|}{$<0.001$} \\
\hline
\end{tabular}

\section{Discussion}

Our aims were to examine whether alcohol exposure in pregnancy, including binge drinking in early pregnancy, affects growth in weight and HC at birth and 5 years, and whether these effects are independent of cigarette exposure in pregnancy and social disadvantage. We found that alcohol consumption up to moderate levels had no independent effects on weight or HC at birth, and there was no evidence of longer-term effects at 5 years. There was an apparent effect of binge drinking on birth weight, but this was due to confounding by cigarette use. Cigarette exposure, not binge drinking, adversely affected HC and birth weight. Univariate analyses of the relationship between alcohol consumption in late pregnancy and HC involved only a small number of cases in the highest level of alcohol consumption, and no differences were evident in the mean z HC scores.

The lack of adverse outcomes due to consumption up to moderate levels is consistent with several previous studies of effects on either weight or $\mathrm{HC}$ in children ranging from birth to 24 months [9,12,24,30-42]. One study that measured children at birth and then again at 6 years also found no effects associated with measures of actual alcohol consumption, although reduced HC and length were associated with a measure of indications of problem drinking [24,51]. Of particular interest is a study that investigated a group who would be considered to be at high risk of adverse outcomes since it involved disadvantaged mothers with a history of alcohol abuse [31]. Although detrimental effects on weight, length, and HC appeared to be due to alcohol consumption, they were no longer significant once covariates such as maternal smoking and race were taken into account.

The results are also partially consistent with several studies of non-disadvantaged samples that, although finding small effects of maternal alcohol consumption on various size parameters at birth, found no conclusive evidence of effects at later ages [12,13,42]. Each of these studies involved cohorts with substantially higher consumption rates than those in the MUSP cohort. In contrast to the findings of the present study, a number of other studies have reported deficits in weight [9-23] and HC $[10,11,15,19,20,22-25,52,53]$ at birth. Again, however, many of these studies found effects at substantially heavier levels of consumption than those reported in the MUSP cohort. Longitudinal research conducted as part of the Maternal Health Practices and Child Development Study (MHPCD) [11,27-29,54-56], for example, has reported a relationship between maternal alcohol consumption and reduced weight, height, and HC at various ages up to 10 years. This research selectively over-sampled heavier drinkers and involved women of low socioeconomic status. Another longitudinal study of disadvantaged women found reduced HC and length at birth [20] and reduced HC in a subset of this sample who were followed up at 5 years [26]. Of concern with the 5-year follow-up study [26], however, is that cigarette use, maternal education, and other lifestyle factors were not controlled for so it is difficult to reach firm conclusions regarding the influence of alcohol alone. Another study [30] of disadvantaged mothers found deficits in weight and length among 6.5-month-old children of mainly older mothers who were very heavy drinkers, consuming an average of 4 or more drinks per day across pregnancy. At 13 months, deficits in length were found only among children of mothers over 30 years of age. Interestingly, Jacobson et al. [30] found that alcohol and smoking did not affect birth size synergistically, and their effects were seen primarily in infants of women more than 30 years of age.

The importance of social disadvantage and maternal smoking is also highlighted by the present findings. Those who were less than 20 years of age, with incomplete high school education, and in the lower third of the cohort in terms of income were more likely to have children with restricted weight and $\mathrm{HC}$ at birth, and smaller HC at 5 years. This is consistent with Day et al.'s [29,44] conclusion that 
growth deficits that persist into childhood tend to be reported in lower SES cohorts.

Previous research has highlighted the detrimental effects of prenatal exposure to nicotine on infant development [47,57]. Further, Haste et al. [34] found that in non-smokers, alcohol consumption had no growth-reducing effect on any birth measurements (length, HC, upper arm circumference, and ponderal index), while in smokers, it appeared to enhance the negative effect of smoking for all measures except HC. The effect of moderate alcohol consumption seemed to be an interactive one since it had no effect on its own. Wright et al. [58] found a significantly increased risk of low birth weight children among mothers drinking more than 10 drinks/week who smoked and were of lower SES. Brooke et al. [9] also found that alcohol had an adverse effect on birth weight only in children of smokers.

Overall, the current findings highlight the predominant influence of factors such as social disadvantage and maternal smoking in producing growth deficits in children, and a lack of effects due to moderate alcohol ingestion. As the seriousness of each risk factor increases, so too does the potential for reduced infant size. As suggested in previous research [31], there may be a threshold effect in relation to alcohol. If consumption exceeds the threshold, then effects may be exhibited, and if a low SES sample is involved, then effects may persist into childhood. Sampson et al. [42] note that some differences between studies may also be due to different analytical strategies.

A strength of the current findings is that they are based on patterns of alcohol consumption among a large sample of the general population, and social differences and cigarette use linked to maternal drinking and child growth outcomes were taken into account when examining effects. Consumption was based on a range of quantity and frequency measures, as well as the frequency of binge drinking. Further, the systematic investigation of a range of potentially confounding factors allowed for competing causes of adverse outcomes to be addressed.

Though the results of this study suggest that moderate levels of alcohol ingestion in pregnancy do not restrict either weight or HC at birth or 5 years, these findings need to be treated cautiously because of a number of study limitations. Firstly, these limitations to inference may arise from the use of self-reports of alcohol consumption and associated threats to the reliability of such reports. Many studies attest to the accuracy of such reports [59-64], although Ernhart et al. [31] investigated this issue among pregnant women and found that higher consumption levels were reported retrospectively in comparison to reports taken during pregnancy. Little et al. [15], however, found no substantial inaccuracies in pregnant women's self-reported alcohol consumption after verification using physical examinations and blood chemistries.

Variability in the accuracy of self-reports is believed to be due to demand characteristics of the situation such as the extent of confidentiality provided [63], the kinds of questions asked, and how far back respondents are asked to recall [61]. We suggest that the assurances of confidentiality and the clinical setting in which information was obtained from respondents who were alcohol-free at the time were all factors that were likely to have maximized the reliability of the current data, although the possibility of under-reporting must be acknowledged. Furthermore, at the time when mothers were first interviewed regarding their alcohol consumption, there was not a widespread knowledge in the community about the relationship between alcohol use and negative outcomes in childhood, thus lending further weight to the accuracy of the self-reports.

Measurement of head circumference at birth may be affected by compression and swelling associated with delivery. Imprecision, though not systematic bias, was introduced by the grouping of head circumference measures to the midpoint of each centimetre interval. Because of ranking, the effects of this will be less apparent using categories based on the 3rd and 10th percentiles. While it is possible that a small effect of alcohol on head circumference may be missed, the lack of association or trend between alcohol in early pregnancy (either glasses per day or binge drinking) and head circumference category makes this unlikely to affect study conclusions.

A further potential weakness of this study is the loss to follow-up. At 5 years, those lost to follow-up were younger, less educated, poorer, and consumed more alcohol, although the magnitude of these differences was generally small. The extent to which the relationships reported would also apply to those children not assessed at 5 years is uncertain, though, as loss to follow up is itself associated with measures of disadvantage, these associations may have been stronger had all children been seen. Though this may alter attributable risk estimates, it is unlikely to alter the conclusion regarding the lack of independent effects of moderate alcohol consumption on weight or HC at birth and the lack of evidence for longer-term effects at 5 years. Given the influence of cigarette smoking and social disadvantage, these factors constitute important areas for intervention. 


\section{Acknowledgements}

The Mater-University Study of Pregnancy was supported by the National Health and Medical Research Council of Australia.

\section{References}

1. Abel EL, Hannigan JH. Maternal risk factors in fetal alcohol syndrome: provocative and permissive influences. Neurotoxicol Teratol 1994;17:445-62.

2. Abel E. Fetal alcohol abuse syndrome. New York (NY): Plenum; 1998.

3. Gabriel K, Hoffmann C, Glavas M, Weinbert J. The hormonal effects of alcohol use on the mother and fetus. Alcohol Health Res World 1998;22:170-8.

4. Michaelis E, Michaelis ML. Cellular and molecular bases of alcohol's teratogenic effects. Alcohol Health Res World 1994;18:17-22.

5. Overholser JC. Fetal alcohol syndrome: a review of the disorder. J Cont Psyt 1990;20:163-76.

6. Fisher S, Atkinson M, Holzman I, David R, Vanthiel D. Effects of ethanol upon placental uptake of amino acids. Prog Biochem Pharmacol 1981;18:216-23.

7. Lin G. Fetal malnutrition: a possible cause of the fetal alcohol syndrome. Prog Biochem Pharmacol 1981;18:115-21.

8. Young NK. Effects of alcohol and other drugs on children. J Psychoact Drugs 1997;29:23-42.

9. Brooke OG, Anderson HR, Bland JM, Peacock JL, Stewart CM. Effects on birth weight of smoking, alcohol, caffeine, socioeconomic factors and psychosocial stress. BMJ 1989;298:795-801.

10. Chernick V, Childiaeva R, Ioffe S. Effects of maternal alcohol intake and smoking on neonatal electroencephalogram and anthropometric measurements. Am J Obstet Gynecol 1983;146:41-7.

11. Day NL, Jasperse D, Richardson G, Robles N, Sambamoorthi U, Taylor P, et al. Prenatal exposure to alcohol: effect on infant growth and morphologic characteristics. Pediatrics 1989;84:536-41.

12. Fried PA, O'Connell CM. A comparison of the effects of prenatal exposure to tobacco, alcohol, cannabis and caffeine on birth size and subsequent growth. Neurotoxicol Teratol 1987;9:79-85.

13. Greene T, Ernhart CB, Ager J, Sokol RJ, Martier S, Boyd T. Prenatal alcohol exposure and cognitive development in the preschool years. Neurotoxicol Teratol 1991;13:57-68.

14. Kuzma JW, Sokol RJ. Maternal drinking behavior and decreased intrauterine growth. Alcohol, Clin Exp Res 1982;6:396402.

15. Little RE, Uhl CN, Labbe RF, Abkowitz JL, Phillips EL. Agreement between laboratory tests and self-reports of alcohol, tobacco, caffeine, marijuana, and other drug use in post-partum women. Soc Sci Med 1986;22:91-8.

16. Lumley J, Correy DJF, Newman NM, Curran JT. Cigarette smoking, alcohol consumption and fetal outcome in Tasmania in 1981-82. Aust NZ Obstet Gynecol 1985;25:33-40.

17. Mills JL, Graubard BI, Harley EE, Rhoads GG, Berends HW. Maternal alcohol consumption and birth weight: how much drinking during pregnancy is safe? JAMA 1984;252:1875-9.

18. Olsen J, Rachootin P, Vibeke Schiodt A. Alcohol use, conception time, and birth weight. J Epidemiol Community Health 1983;37:63-5.

19. Rosett HL, Weiner L, Lee A, Zuckerman B, Dooling E, Oppenheimer E. Patterns of alcohol consumption and fetal development. Obstet Gynecol 1983;61:539-46.

20. Smith IE, Coles CD, Lancaster J, Fernhoff PM, Falek A. The effect of volume and duration of prenatal ethanol exposure on neonatal physical and behavioral development. Neurobehav Toxicol Teratol 1986;8:375-81.

21. Sokol RJ, Miller SI, Reed G. Alcohol abuse during pregnancy: an epidemiologic study. Alcohol, Clin Exp Res 1980;4:13545.

22. Streissguth AP, Martin DC, Martin JC, Barr HM. The Seattle longitudinal prospective study on alcohol and pregnancy. Neurobehav Toxicol Teratol 1981;3:223-33.

23. Godel JC, Pabst HF, Hodges PE, Johnson KE, Froese GJ, Joffres MR. Smoking and caffeine and alcohol intake during pregnancy in a northern population: effect on fetal growth. Can Med Assoc J 1992;147:181-8.

24. Russell M, Skinner JB. Early measures of maternal alcohol misuse as predictors of adverse pregnancy outcomes. Alcohol, Clin Exp Res 1988;12:824-30.

25. Sulaiman ND, Florey CV, Taylor DJ, Ogston SA. Alcohol consumption in Dundee primigravidas and its effects on outcome of pregnancy. Br Med J 1988;296:1500-3.

26. Coles CD, Brown RT, Smith IE, Platzman KA, Erickson S, Falek A. Effects of prenatal alcohol exposure at school age: I. Physical and cognitive development. Neurotoxicol Teratol 1991;13:357-67.

27. Day NL, Goldschmidt L, Robles N, Richardson G, Cornelius M, Taylor P, et al. Prenatal alcohol exposure and offspring growth at 18 months of age: the predictive validity of two measures of drinking. Alcohol, Clin Exp Res 1991;15:914-8.

28. Day NL, Richardson GA, Geva D, Robles N. Alcohol, marijuana, and tobacco: effects of prenatal exposure on offspring growth and morphology at age six. Alcohol, Clin Exp Res 1994;18:786-94.

29. Day NL, Zuo Y, Richardson GA, Goldschmidt L, Larkby CA, Cornelius M. Prenatal alcohol use and offspring size at 10 years of age. Alcohol, Clin Exp Res 1999;23:863-9.

30. Jacobson JL, Jacobson SW, Sokol RS, Martier SS, Ager JW, Shankaran S. Effects of alcohol use, smoking, and illicit drug use on fetal growth in black infants. J Pediatr 1994;124:757-64.

31. Ernhart CB, Wolf AW, Linn PL, Sokol RJ, Kennard MJ, Filipovich HF. Alcohol-related birth defects. Syndromal anomalies, intrauterine growth retardation, and neonatal behavioral assessment. Alcohol, Clin Exp Res 1985;9:447-53.

32. Galbraith RS, Karchmar EJ, Piercy WN, Low JA. The clinical prediction of intrauterine growth retardation. Am J Obstet 
Gynecol 1979;133:281-6.

33. Grisso JA, Roman E, Inskip H, Beral V, Donovan J. Alcohol consumption and outcome of pregnancy. J Epidemiol Community Health 1984;38:232-5.

34. Haste FM, Anderson HR, Brooke OG, Bland JM, Peacock JL. The effects of smoking and drinking on the anthropometric measurements of neonates. Paediatr Perinat Epidemiol 1991;5:83-92.

35. Hingson R, Alpert JJ, Day N, Dooling E, Kayne H, Morelock S, et al. Effects of maternal drinking and marijuana use on fetal growth and development. Pediatrics 1982;70:539-46.

36. Kline J, Levin B, Stein Z, Susser M, Warburton D. Epidemiologic detection of low dose effects on the developing fetus. Environ Health Perspect 1981;42:119-26.

37. Marbury MC, Linn S, Monson R, Schoenbaum S, Stubblefield PG, Ryan KJ. The association of alcohol consumption with outcome of pregnancy. Am J Public Health 1983;73:1165-8.

38. Rostand A, Kaminski M, Lelong N, et al. Alcohol use in pregnancy, craniofacial features, and fetal growth. J Epidemiol Community Health 1990;44:302-6.

39. Tennes K, Blackard C. Maternal alcohol consumption, birth weight, and minor physical anomalies. Am J Obstet Gynecol 1980;138:774-80.

40. Walpole I, Zubrick S, Pontre J. Is there a fetal effect with low to moderate alcohol use before or during pregnancy? J Epidemiol Community Health 1990;44:297-301.

41. O’Connor MJ, Brill NJ, Sigman M. Alcohol use in primiparous women older than 30 years of age: relation to infant development. Pediatrics 1986;78:444-50.

42. Sampson PD, Bookstein FL, Barr HM, Streissguth AP. Prenatal alcohol exposure, birthweight, and measures of child size from birth to age 14 years. Am J Public Health 1994;84:1421-8.

43. Poskitt EME. Fetal alcohol syndrome. Alcohol Alcohol 1984;19:150-65.

44. Day N. The effects of prenatal exposure to alcohol. Alcohol Health Res World 1992;16:238-44.

45. Keeping JD, Najman JM, Morrison J, Western JS, Andersen MJ, Williams GM. A prospective longitudinal study of social, psychological and obstetric factors in pregnancy: response rates and demographic characteristics of the 8556 respondents. Br $\mathrm{J}$ Obstet Gynaecol 1989;96:289-97.

46. O’Callaghan MJ, Williams GM, Andersen MJ, Bor W, Najman JM. Social and biological risk factors for mild and borderline impairment of language comprehension in a cohort of children at 5 years. Dev Med Child Neurol 1995;37:105161 .

47. Williams GM, O’Callaghan M, Najman JM, Bor W, Andersen MJ, Richards D, et al. Maternal cigarette smoking and child psychiatric morbidity: a longitudinal study. Pediatrics 1998;102:1-8.

48. Freeman JV, Cole TJ, Chinn S, Jones PRM, White EM, Preece MA. Cross-sectional stature and weight reference curves for the UK 1990. Arch Dis Child 1995;73:17-24.

49. Jessor R, Graves TD, Hanson RC, Jessor SL. Procedures used for devising quantity-frequency indexes of alcohol use in both the community survey and the high school studies. Society, personality, and deviant behavior: a study of a tri-ethnic community. New York (NY): Hold, Rinehard \& Winston; 1968. p. 483-6.

50. Kahn HA, Sempos CT. Statistical methods in epidemiology. Oxford (UK): Oxford Univ. Press; 1989.

51. Russell M, Czarnecki DM, Cowan R, McPherson E, Mudar PJ. Measures of maternal alcohol use as predictors of development in early childhood. Alcohol, Clin Exp Res 1991;15:991-1000.

52. Streissguth AP, Barr HM, Sampson PD, Parrish-Johnson JC, Kirchner GL, Martin DC. Attention, distraction and reaction time at age 7 years and prenatal alcohol exposure. Neurobehav Toxicol Teratol 1986;8:717-25.

53. Streissguth AP, Sampson PD, Carmichael Olson HC, Bookstein FL, Barr HM, Scott M, et al. Maternal drinking during pregnancy: attention and short-term memory in 14-year-old offspring-A longitudinal prospective study. Alcohol, Clin Exp Res 1994;18:202-18.

54. Day NL, Richardson GA, Robles N, Sambamoorthi U, Taylor P, Scher M, et al. Effect of prenatal alcohol exposure on growth and morphology of offspring at 8 months of age. Pediatrics 1990;85:748-52.

55. Day NL, Robles N, Richardson G, Geva D, Taylor M, Scher D, et al. The effects of prenatal alcohol use on the growth of children at three years of age. Alcohol, Clin Exp Res 1991;15:67-71.

56. Geva D, Goldschmidt L, Stoffer D, Day NL. A longitudinal analysis of the effect of prenatal alcohol exposure on growth. Alcohol, Clin Exp Res 1993;17:1124-9.

57. Ernst J, Moolchan ER, Robinson ML. Behavioral and neural consequences of prenatal exposure to nicotine. J Am Acad Child Adolesc Psych 2001;40:630-41.

58. Wright JT, Barrison IG, Waterson EJ, et al. Alcohol-consumption, pregnancy and low-birthweight. Lancet 1983;1:663-5.

59. Babor TF, Stephens RS, Marlatt GA. Verbal report methods in clinical research on alcoholism: response bias and its minimization. J Stud Alcohol 1987;48:410-24.

60. Czarnecki DM, Russell M, Cooper ML, Salter D. Five-year reliability of self-reported alcohol consumption. J Stud Alcohol 1990;51:68-76.

61. Harris TR, Wilsnack RW, Klassen AD. Reliability of retrospective self-reports of alcohol consumption among women: data from a U.S. national sample. J Stud Alcohol 1994;55:309-14.

62. Sobell LC, Sobell MB. Self-report issues in alcohol abuse: state of the art and future directions. Behav Assess 1990;12:7790 .

63. Werch CE. Two procedures to reduce response bias in reports of alcohol consumption. J Stud Alcohol 1990;51:327-30.

64. Williams GD, Aitken SS, Malin H. Reliability of self-reported alcohol consumption in a general population survey. J Stud Alcohol 1985;46:223-7. 